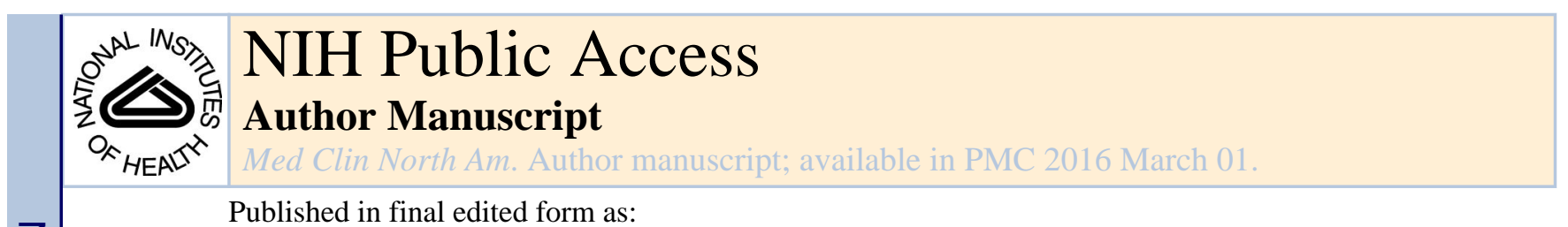

Published in final edited form as:

Med Clin North Am. 2015 March ; 99(2): 417-430. doi:10.1016/j.mcna.2014.11.012.

\title{
Anti-Thrombotic Management of Atrial Fibrillation in the Elderly
}

\author{
Karli Edholm ${ }^{1}$, Nathan Ragle ${ }^{1}$, and Matthew T. Rondina ${ }^{1,2}$ \\ ${ }^{1}$ Division of General Internal Medicine, University of Utah School of Medicine, Salt Lake City, \\ Utah \\ ${ }^{2}$ Program in Molecular Medicine, University of Utah School of Medicine, Salt Lake City, Utah
}

\section{SYNOPSIS}

Compared to younger patients, older patients with atrial fibrillation (AF) have an increased risk of stroke and systemic embolism ${ }^{1,2}$. For the majority of patients, oral anticoagulation (OAC) remains the most effective way to reduce this risk. While vitamin $\mathrm{K}$ antagonists (VKAs) have been used for decades, the more recent development of non-vitamin $\mathrm{K}$ dependent oral anticoagulants (NOACs) provides clinicians with broader selection of anticoagulants for stroke prevention in older AF patients. In this review, we discuss stroke risk-stratification tools for clinical decision making, review pharmacologic options for the prevention of stroke, and highlight several practical considerations to the use of these agents in older adults.

\section{Keywords}

Anticoagulation; Atrial Fibrillation; Elderly; Bleeding; Warfarin; Antiplatelet Agents; Risk Stratification

\section{INTRODUCTION}

$\mathrm{OAC}$ is the most effective way to prevent thromboembolic disease in patients with $\mathrm{AF}^{1}$. For decades, aspirin and VKAs were the primary agents used to prevent thromboembolic disease in patients with AF. The approval of NOACs has now expanded the range of therapeutic agents available to providers. Nevertheless, the safe and effective use of NOACs in older adults remains less well established and understood, despite the marked increase in the prevalence of both $\mathrm{AF}$ and $\mathrm{AF}-$ associated thromboembolism in this population ${ }^{1-4}$. In this review, we discuss strategies to assess bleeding and thrombosis risk in older adults with $\mathrm{AF}$ and summarize pharmacologic options for the prevention of stroke, TIA, and systemic embolism. We will highlight practical considerations to the selection and use of these agents in older adults to aid clinical decision making.

(C) 2014 Elsevier Inc. All rights reserved.

Corresponding Author: Matthew T. Rondina, M.D., University of Utah, Department of Internal Medicine, Eccles Institute of Human Genetics, 15 North 2000 East, Suite 4220, SLC, Utah 84112, (801) 585-0950 (phone), (801) 585-1393 (fax), matthew.rondina@hsc.utah.edu.

Publisher's Disclaimer: This is a PDF file of an unedited manuscript that has been accepted for publication. As a service to our customers we are providing this early version of the manuscript. The manuscript will undergo copyediting, typesetting, and review of the resulting proof before it is published in its final citable form. Please note that during the production process errors may be discovered which could affect the content, and all legal disclaimers that apply to the journal pertain. 


\section{MANAGEMENT GOALS}

The aim of OAC is to prevent the devastating consequences of stroke in older adults with AF while minimizing complications from treatment. Older patients are at increased risk of bleeding complications, adding to the complexity of their treatment. The decision to use antithrombotic therapy in an individual patient with $\mathrm{AF}$ requires an estimate of the baseline stroke risk without treatment and the risk of bleeding (especially intracranial hemorrhage ICH) with treatment, followed by determination of the patient's values and preferences through shared decision-making. Periodic re-evaluation of the patient's stroke and bleeding risk is essential ${ }^{1}$. Unfortunately, there are still important limitations to accomplishing these goals.

\section{Stroke Risk Assessment}

Stroke risk in individual AF patients varies from less than 1\% per year to more than $18 \%$ per year and depends on the presence, number, and relative predictive strength of different clinical risk factors for stroke, and not on whether AF is paroxysmal, persistent, or permanent. The strongest risk factors are the presence of mechanical heart valves or mitral stenosis, and these patients all require $\mathrm{OAC}^{1}$. For patients with nonvalvular $\mathrm{AF}$, the four strongest stroke predictors are prior stroke and/or TIA $(R R=2.5)$, hypertension $(R R=2.0)$, diabetes mellitus $(\mathrm{RR}=1.7)$, and age $(\mathrm{RR}=1.5 \text { per decade })^{2}$.

These clinical risk factors have been variably combined into different stroke risk stratification tools, including the $\mathrm{CHADS}_{2}$ and $\mathrm{CHA}_{2} \mathrm{DS}_{2}$-VASc (Tables $\left.1 \& 2\right)^{5,6}$. The $\mathrm{CHA}_{2} \mathrm{DS}_{2}$-VASc adds female sex, vascular disease and age 65-74 to the risk factors included in the $\mathrm{CHADS}_{2}$ score. A systematic review of validation studies concluded that these two tools have the best - albeit modest - discrimination ability for stroke (c-statistics of 0.71 and 0.70 , respectively) ${ }^{7}$. Current clinical practice guidelines recommend the use of $\mathrm{CHA}_{2} \mathrm{DS}_{2}$-VASc over $\mathrm{CHADS}_{2}$ due to several advantages ${ }^{1,8-10}$. Older age ( 275 years) is the single most important risk factor for stroke (4.0-5.0\%/yr, HR 3.0-3.5), greater than hypertension, diabetes, or heart failure, thereby warranting extra weight ( 2 points) as a risk factor ${ }^{11,12}$. While the two scores provide similar identification of AF patients at high stroke risk, use of $\mathrm{CHA}_{2} \mathrm{DS}_{2}$-VASc improves stratification of patients considered "low" (score $=0$ ) and "intermediate" (score=1) risk by $\mathrm{CHADS}_{2}{ }^{11,13}$. $\mathrm{CHA}_{2} \mathrm{DS}_{2}$-VASc identifies up to $22 \%$ of AF patients with a CHADS 2 score of 0 whose annual event rate may not be low $(0.84 \%$ for $\mathrm{CHA}_{2} \mathrm{DS}_{2}$-VASc score $=0$ to $3.2 \%$ for $\mathrm{CHA}_{2} \mathrm{DS}_{2}$-VASc score $=3$ ), and may benefit from $\mathrm{OAC}^{11,13}$. Thus, $\mathrm{CHA}_{2} \mathrm{DS}_{2}$-VASc better identifies the "truly low risk" cohort whose annual event rate is $<1 \%$, and in whom anticoagulation can be safely deferred $11,14,15$.

Current guidelines for antithrombotic therapy in non-valvular AF vary in their recommendations (Table 3) ${ }^{1,8-10}$. For a $\mathrm{CHA}_{2} \mathrm{DS}_{2}$-VASc score of 0 , no antithrombotic therapy (including no aspirin) is recommended. For a score of $\geq 2$, all recommend some form of OAC, with NOACs generally preferred over warfarin. However, there is no consensus on OAC for patients with a $\mathrm{CHA}_{2} \mathrm{DS}_{2}$-VASc score of 1 . The 2014 American Heart Association/American College of Cardiology/Heart Rhythm Society guidelines (AHA/ACC/HRS-2014) suggest that clinicians "consider" the options of no antithrombotic therapy versus OAC versus aspirin for these patients ${ }^{1}$. In contrast, the 2014 National 
Institute for Health and Care Excellence (NICE) ${ }^{10}$, the 2012 Canadian Cardiovascular Society $(\mathrm{CCS})^{8}$, and the 2012 European Society of Cardiology (ESC) ${ }^{9}$ guidelines recognize that women with $\mathrm{AF}<65$ years with no other stroke risk factors are at very low risk of stroke and should not receive any antithrombotic therapy ${ }^{16,17}$. The NICE guideline states that OAC be "considered" for men with a $\mathrm{CHA}_{2} \mathrm{DS}_{2}-\mathrm{VASc}$ score of 1 while the ESC "recommends" OAC for them. Because AF patients age 65-74 years with no other stroke risk factors have annual stroke rates of about $2 \%$ per year ${ }^{12}$, the CCS "recommends" OAC for them but not for patients whose only risk factor by $\mathrm{CHA}_{2} \mathrm{DS}_{2}$-VASc is female sex or vascular disease.

\section{Bleeding Risk Assessment}

An AF patient's risk of fatal or disabling bleeding must be assessed when making decisions about antithrombotic therapy. A recent systematic review concluded that the HAS-BLED score (Tables $4 \& 5$ ) provides the best, although modest (c-statistic 0.58-0.80), estimation of major bleeding risk for warfarin OAC in AF patients ${ }^{7,18}$. However, the HAS-BLED and other bleeding risk scores have important limitations. At least $80 \%$ of major bleeds predicted by these tools are extracranial hemorrhages (especially gastrointestinal) that carry low rates of mortality $(<5-6 \%)$ and rare disability ${ }^{19}$. Of much greater concern are ICHs, which constitute 15-20\% of major bleeds during warfarin treatment and are responsible for $90 \%$ of fatal bleeds ${ }^{19}$. ICH carries rates of mortality and severe disability of $46 \%$ and $22 \%$, respectively, in AF patients treated with warfarin ${ }^{20}$.

None of the bleeding risk scores can quantitatively estimate absolute ICH risk, nor can these scores identify AF patients in whom the risk of ICH plus fatal or disabling extracranial hemorrhage is likely to exceed the risk of fatal or disabling ischemic stroke. Additionally, these bleeding risk scores have been validated for warfarin OAC but not yet for NOACs. One recent guideline suggests that current bleeding risk scores do not have sufficient clinical utility to recommend their use ${ }^{1}$. Most current recommendations suggest that the HAS-BLED score not be used to exclude patients from OAC, but rather to systematically identify and then eliminate modifiable bleeding risk factors such as uncontrolled hypertension, inadequate warfarin anticoagulation with labile INRs, unnecessary concomitant use of aspirin or NSAIDS, and excessive alcohol use ${ }^{8-10}$.

\section{PHARMACOLOGIC STRATEGIES}

The elderly present a unique challenge in antithrombotic management, due to the frequency of associated co-morbidities that increase the risk of both stroke and bleeding, multiple drug therapy, concerns about compliance and cognitive impairment, low body weight, increased risk of falls, and decreased renal clearance of medications.

\section{Oral Anticoagulation with Warfarin}

Underutilization-Compared to no treatment, warfarin decreases the risk of stroke by approximately $2 / 3$ and death by $1 / 4$, with an average number needed to treat (NNT) for 1 year to prevent 1 stroke of $37^{21}$. Despite compelling evidence of the benefits of warfarin on stroke prevention, it remains underutilized, with estimates that less than $1 / 2$ of eligible AF 
patients without contraindications are receiving treatment ${ }^{22,23}$. The challenges with warfarin are well-known and include unpredictable pharmacodynamics and pharmacokinetics, narrow therapeutic window, and numerous drug-drug and food-drug interactions, which necessitate frequent laboratory monitoring and dose adjustments.

Also contributing to suboptimal warfarin utilization are patient and physician fears of bleeding. Physicians are less likely to anticoagulate older patients, even in the absence of contraindications, due to the perception that the risks of treatment outweigh the benefits ${ }^{23,24}$. Each advancing decade of life is associated with a $14 \%$ reduction in warfarin use, independent of other risk factors for stroke ${ }^{3}$. Additionally, patients frequently refuse anticoagulation. For example, 1/3 of patients enrolled in the AVERROES and ACTIVE A studies refused a VKA, due to the associated inconvenience and perceived bleeding risk $^{25,26}$.

Fear of Falls-Clinicians may disproportionately consider the risk of traumatic ICH from falls in their assessment of the net clinical benefit of OAC for older AF patients. Clinician perception of fall risk is a key determinant in their decision to use $\mathrm{OAC}^{24}$. However, studies of $\mathrm{AF}$ patients on $\mathrm{OAC}$ and who are at high fall risk do not consistently demonstrate an increased risk of traumatic $\mathrm{ICH}^{27}$. A modeling study suggested that $\mathrm{AF}$ patients at higher risk of stroke would have to fall > 295 times/year before the risk of traumatic ICH would exceed the risk of ischemic stroke; yet, in older persons who fall, the mean number of falls is only $1.8 /$ year $^{28,29}$. In older Medicare beneficiaries with traumatic brain injury on OAC, resumption of warfarin therapy following hospital discharge resulted in a 17\% reduction in the combined outcome of ischemic and hemorrhagic stroke ${ }^{30}$. Based on these data, many investigators propose that high fall risk is not a reason to avoid $\mathrm{OAC}^{10,27,28}$. For clinicians with significant concerns about individual patients, a referral to a faint and fall clinic or a comprehensive fall risk assessment can be considered.

Net clinical benefit of warfarin-Based on the need to balance the risks of ischemic thromboembolism (TE) with the risks of fatal and disabling major bleeding, prospective cohort studies of AF patients have assessed the "net clinical benefit" of warfarin. This has been established as the annual rate of ischemic strokes prevented by warfarin minus the annual rate of ICH caused by warfarin, the latter multiplied by a factor of 1.5 to reflect the greater clinical severity of ICH than ischemic stroke ${ }^{16,31,32}$. Overall, the impact of warfarin is much higher on TE risk than on ICH risk ${ }^{31}$. Due to increasing risk for stroke with aging and a relatively constant increase in ICH risk with aging, the net clinical benefit of warfarin improves progressively with advancing age and is greatest for AF patients $\geq 85^{31}$. Net clinical benefit of warfarin also improves progressively with major bleeding risk as measured by the HAS-BLED score; that is, warfarin OAC decreases ischemic stroke rate more than it increases ICH rate at all levels of bleeding risk ${ }^{16,32}$., Moreover the net clinical benefit of warfarin is favorable in all groups except with $\mathrm{CHA}_{2} \mathrm{DS}_{2}-\mathrm{VASc}$ score of 0 , confirming their "truly low risk" status ${ }^{16,32}$. In this large study, only $0.4 \%$ of patients had a bleeding risk exceeding their stroke risk ${ }^{16}$. Thus, in almost all AF patients, particularly the elderly and those at high bleeding risk, the risk of ischemic stroke without OAC exceeds the risk of intracranial bleeding with OAC. 
Reflective of this data, the pendulum in antithrombotic management is swinging away from a focus on identifying high-risk patients for treatment with $\mathrm{OAC}$, and towards identification of the "truly low risk" patient, in whom OAC can safely be deferred, while considering all other patients for anticoagulation treatment. Use of the $\mathrm{CHA}_{2} \mathrm{DS}_{2}$-VASc scoring system can help in identifying this subgroup of patients.

\section{Antiplatelet Therapy}

Aspirin monotherapy-In some settings, aspirin has been historically considered a safer alternative to $\mathrm{OAC}^{24}$. Aspirin was previously recommended for stroke prevention in patients considered low-risk for stroke, and seen as an acceptable alternative to OAC for patients at intermediate risk of stroke and for those who were deemed unsuitable for, or choose not to take warfarin ${ }^{33}$. There is moderate evidence from numerous RCTs that aspirin decreases the risk of nonfatal stroke by $21 \%$ compared to no therapy, but at a cost of a $50-60 \%$ increase in major extracranial bleeding ${ }^{21,34}$. However, in comparison to aspirin monotherapy, warfarin is superior, with a $37 \%$ greater reduction in strokes ${ }^{21}$. The relative risk of ICH is doubled with warfarin compared to aspirin, but this represents only a small absolute increase $(0.2-$ $0.4 \% /$ year $)^{21}$.

Efficacy data for aspirin use in the elderly is even less compelling. In the BAFTA trial, patients aged $\geq 75$ years were randomized to either warfarin or aspirin $75 \mathrm{mg}$ daily. Warfarin was associated with a significant reduction in fatal or disabling stroke, ICH, or systemic embolus (1.8 vs 3.8\%/year; RR 0.48, NNT 50), with a similar risk of major hemorrhage ${ }^{35}$. The yearly risk of a major bleed on aspirin was not insignificant, at $2 \%$ per year ${ }^{35}$. Other studies have also demonstrated higher rates of side-effects and intolerance to aspirin than warfarin $^{36}$.

In a net clinical benefit analysis, aspirin was not found to be protective of thromboembolism, with an increased bleeding risk compared to no treatment, and a similar bleeding risk to warfarin, leading the authors to suggest that aspirin should not be used for any patient with $\mathrm{AF}^{32}$. Aspirin is significantly less effective at stroke prevention than warfarin in older patients, with no difference in major bleeding ${ }^{4}, 35$. Additionally, the relative benefit of antiplatelet therapy has been shown to decrease significantly with age, but the relative benefit of warfarin does not ${ }^{4}$. Since stroke risk increases with age, the absolute benefit of OAC over antiplatelet therapy continues to increase as patients age ${ }^{4}$. Reflective of this, some guidelines no longer recommend use of aspirin as an acceptable alternative to $\mathrm{OAC}^{9,10,34}$.

Dual antiplatelet therapy-Compared to aspirin monotherapy, dual antiplatelet therapy offers superior stroke prevention ( $2.4 \mathrm{vs} \mathrm{3.3 \% /yr,} \mathrm{RR} \mathrm{0.72),} \mathrm{albeit} \mathrm{as} \mathrm{the} \mathrm{expense} \mathrm{of}$ increased major bleeding ( $2.0 \mathrm{vs} 1.3 \% / \mathrm{yr}$, RR 1.57$)$ and ICH $(0.4 \text { vs } 0.2 \% / \mathrm{yr}, \mathrm{RR} 1.87)^{25}$. The ACTIVE $\mathrm{W}$ trial evaluated dual antiplatelet therapy as a potential alternative to warfarin in AF patients at high risk of stroke ${ }^{37}$. This trial was stopped early as warfarin significantly reduced the risk of stroke by $42 \%$ compared to aspirin plus clopidogrel (3.93 vs 5.60\%/yr, NNT 100), with no difference in mortality or major bleeding. Similar data was seen when apixaban was compared to the combination of aspirin and clopidogrel in the AVERROES 
trial, which was terminated prematurely due to a 50\% reduction in stroke rate with apixaban, without any differences in bleeding. Apixaban was also associated with fewer adverse events and a lower rate of discontinuation ${ }^{26}$.

For patients who refuse OAC or are deemed unsuitable candidates for reasons other than bleeding risk, the combination of aspirin and clopidogrel should be considered, and this is now recommended in some guidelines over aspirin monotherapy 9,34 . Patients should be counseled that this regimen offers inferior stroke prevention compared to OAC, with no difference in bleeding risk.

\section{Non-vitamin K dependent oral anticoagulants (NOACs)}

Recently, the FDA has approved three NOACs (dabigatran, rivaroxaban and apixaban) for use in AF, with an additional agent (edoxaban) expected to be available in the near future (Table 6). These newer drugs provide clinicians with additional therapeutic options to prevent stroke in AF, and lack many of the limitations inherent to warfarin. They have predictable pharmacodynamic and pharmacokinetic profiles, a wide therapeutic window, shorter half-life with rapid onset/offset of action, less drug-drug interactions, few to no fooddrug interactions, no need for routine laboratory monitoring, and fixed dosing schedules.

Dabigatran is an oral direct thrombin inhibitor, while rivaroxaban, apixaban and edoxaban are Factor Xa inhibitors. Each of these drugs are either non-inferior or superior to warfarin for stroke prevention, with markedly less intracranial bleeding (Table 7) ${ }^{38-41}$. Dabigatran, rivaroxaban, and edoxaban caused higher rates of GI bleeding than warfarin. To better define the efficacy and safety of these medications in subgroups, meta-analyses of these phase 3 clinical trials have been performed ${ }^{42,43}$. NOACs are associated with an approximately $12 \%$ decrease in mortality compared to warfarin, a $20 \%$ decrease in stroke or systemic embolus, and most impressively, a 50\% reduction in ICH. The net clinical benefit of NOACs is not yet as clearly established as it is for warfarin. However, due to their 50\% lower risk of $\mathrm{ICH}$, modeling analyses suggest that NOACs may provide even greater net clinical benefit than warfarin for AF patients with a $\mathrm{CHA}_{2} \mathrm{DS}_{2}$-VASc score $\geq 1^{44}$.

Efficacy and Safety of NOACs in Older Patients-Although there are no RCTs that have enrolled exclusively older patients with AF, the available evidence suggests that the safety and efficacy of NOACs in older adults is similar to the overall study population ${ }^{45}$. A recent meta-analysis of randomized trials of NOACs in patients $\geq 75$ years showed significantly lower rates of stroke and systemic embolus compared to conventional treatment, with no increased risk of bleeding ${ }^{46}$. In the ROCKET AF trial, the risk of any major bleeding was similar among patients who received rivaroxaban or warfarin, regardless of age, but intracranial bleeding was lower with rivaroxaban ${ }^{39,47}$. In ARISTOTLE, the overall risk of stroke, death, and major bleeding increased with aging, but apixaban was more effective than warfarin in reducing these outcomes, irrespective of age ${ }^{40,48}$. Due to increasing risk of stroke as patients age, the absolute benefit of NOACs over warfarin was greatest in the elderly. In contrast to rivaroxaban and apixaban, in the RE-LY trial, there was a highly significant interaction between treatment and age for major bleeding. In patients < 75 , both doses of dabigatran were associated with a lower risk of major bleeding compared 
to warfarin. However, patients $\geq 75$ years experienced similar rates of major extracranial bleeding compared to warfarin with dabigatran at a dose of $110 \mathrm{mg}$ twice daily, but a trend toward higher risk of extracranial bleeding with the $150 \mathrm{mg}$ twice daily. ICH was reduced with both doses of dabigatran compared to warfarin, regardless of age ${ }^{38,49}$. These data suggest that the safety of Xa inhibitors is less dependent on age than is dabigatran, with one possible explanation being that they are less dependent on renal clearance than dabigatran ${ }^{48}$.

Disadvantages of NOACS—The potential disadvantages associated with the NOACs include twice daily dosing regimen (with the exception of rivaroxaban), short duration of action, lack of a reliable and readily available monitoring option, and lack of antidote (Table 8). Discussion of potential laboratory monitoring and reversal agents is beyond the scope of this article. We have chosen to focus on renal impairment, since renal function declines with advancing age and patients with severe renal impairment $(\mathrm{CrCl}<30 \mathrm{~mL} / \mathrm{min},<25 \mathrm{~mL} / \mathrm{min}$ for apixaban) were excluded from the clinical trials.

NOACs in older patients with renal impairment-NOACs have not yet been robustly studied in patients with severe renal impairment and are not recommended in patients with end-stage renal disease or on hemodialysis. The incidence of renal impairment increases with age, and renal impairment increases the risk of both thromboembolism and bleeding complications in patients with AF, independent of other risk factors ${ }^{49,50}$. Since AF is primarily a disease of the elderly, these two conditions often coexist, leading to significant concerns about bleeding risk. In RE-LY, patients on either dabigatran or warfarin with a $\mathrm{CrCl}<50 \mathrm{~mL} / \mathrm{min}$ experienced a 2 -fold higher risk of major bleeding, compared to those who had a $\mathrm{CrCl} \geq 80 \mathrm{~mL} / \mathrm{min}^{49}$. In ROCKET-AF, reduced dose rivaroxaban in patients with $\mathrm{CrCl} 30-49 \mathrm{~mL} / \mathrm{min}$ preserved the benefit over warfarin without increasing bleeding and with fewer fatal bleeds ${ }^{51}$. In ARISTOTLE, apixaban reduced the rate of stroke, death and major bleeding compared to warfarin regardless of renal function, including in patients > $75^{48,50}$. Thus, all three trials showed higher rates of bleeding and stroke with impaired renal function regardless of randomized treatment assignment, suggesting no increased risk with NOACs as compared to warfarin.

Although NOACs appear to be at least as safe as warfarin in the short-term and reduce the risk of intracranial bleeding, longer-term data is still needed. There may also be subtle differences between the NOACs in rates of ischemic stroke, MI, bleeding and death, but the lack of head-to-head trials makes this difficult to discern. Nevertheless, when considered overall, the significant decrease in $\mathrm{ICH}$, fixed dosing schedules, lack of routine laboratory monitoring, and fewer drug-drug interactions make the NOACs an alternative to warfarin for some older patients (Table 8).

\section{Future Considerations and Summary}

In summary, age remains one of the strongest risk factors for stroke in patients with AF. The use of guideline-recommended stroke scoring systems, in combination with a bleeding risk factor assessment can help guide providers in determining the net clinical benefit of antithrombotic therapy in older adults with AF. Recently approved NOACs may offer select 
advantages for the prevention of stroke and systemic embolism in older patients with AF. Future studies may further elucidate the net clinical benefit of NOACs in the elderly and help guide more individualized $\mathrm{AC}$ selection and management.

\section{Acknowledgments}

This work was supported by the National Institutes of Health and the National Institute of Aging (HL092161, AG040631, HL112311, and AG048022) and the University of Utah Center on Aging. We thank Dr. Barry Stults for his valuable comments and expert suggestions.

\section{References}

1. January CT, Wann LS, Alpert JS, et al. AHA/ACC/HRS Guideline for the Management of Patients With Atrial Fibrillation: A Report of the American College of Cardiology/American Heart Association Task Force on Practice Guidelines and the Heart Rhythm Society. Circulation. 2014

2. Stroke Risk in Atrial Fibrillation Working G. Independent predictors of stroke in patients with atrial fibrillation: a systematic review. Neurology. 2007; 69(6):546-554. [PubMed: 17679673]

3. Brophy MT, Snyder KE, Gaehde S, et al. Anticoagulant use for atrial fibrillation in the elderly. Journal of the American Geriatrics Society. 2004; 52(7):1151-1156. [PubMed: 15209654]

4. van Walraven C, Hart RG, Connolly S, et al. Effect of age on stroke prevention therapy in patients with atrial fibrillation: the atrial fibrillation investigators. Stroke; a journal of cerebral circulation. 2009; 40(4):1410-1416.

5. Gage BF, Waterman AD, Shannon W, et al. Validation of clinical classification schemes for predicting stroke: results from the National Registry of Atrial Fibrillation. JAMA : the journal of the American Medical Association. 2001; 285(22):2864-2870.

6. Lip GY, Nieuwlaat R, Pisters R, et al. Refining clinical risk stratification for predicting stroke and thromboembolism in atrial fibrillation using a novel risk factor-based approach: the euro heart survey on atrial fibrillation. Chest. 2010; 137(2):263-272. [PubMed: 19762550]

7. Lopes, RD.; Crowley, MJ.; Shah, BR., et al. Stroke Prevention in Atrial Fibrillation. Rockville (MD): 2013.

8. Skanes AC, Healey JS, Cairns JA, et al. Focused 2012 update of the Canadian Cardiovascular Society atrial fibrillation guidelines: recommendations for stroke prevention and rate/rhythm control. The Canadian journal of cardiology. 2012; 28(2):125-136. [PubMed: 22433576]

9. Camm AJ, Lip GY, De Caterina R, et al. 2012 focused update of the ESC Guidelines for the management of atrial fibrillation: an update of the 2010 ESC Guidelines for the management of atrial fibrillation. Developed with the special contribution of the European Heart Rhythm Association. European heart journal. 2012; 33(21):2719-2747. [PubMed: 22922413]

10. Jones C, Pollit V, Fitzmaurice D, et al. The management of atrial fibrillation: summary of updated NICE guidance. Bmj. 2014; 348:g3655. [PubMed: 24948694]

11. Olesen JB, Lip GY, Hansen ML, et al. Validation of risk stratification schemes for predicting stroke and thromboembolism in patients with atrial fibrillation: nationwide cohort study. Bmj. 2011; 342:d124. [PubMed: 21282258]

12. Olesen JB, Fauchier L, Lane DA, et al. Risk factors for stroke and thromboembolism in relation to age among patients with atrial fibrillation: the Loire Valley Atrial Fibrillation Project. Chest. 2012; 141(1):147-153. [PubMed: 21680645]

13. Olesen JB, Torp-Pedersen C, Hansen ML, et al. The value of the CHA2DS2-VASc score for refining stroke risk stratification in patients with atrial fibrillation with a CHADS2 score 0-1: a nationwide cohort study. Thrombosis and haemostasis. 2012; 107(6):1172-1179. [PubMed: 22473219]

14. Friberg L, Rosenqvist M, Lip GY. Evaluation of risk stratification schemes for ischaemic stroke and bleeding in 182678 patients with atrial fibrillation: the Swedish Atrial Fibrillation cohort study. European heart journal. 2012; 33(12):1500-1510. [PubMed: 22246443] 
15. Singer DE, Chang Y, Borowsky LH, et al. A new risk scheme to predict ischemic stroke and other thromboembolism in atrial fibrillation: the ATRIA study stroke risk score. Journal of the American Heart Association. 2013; 2(3):e000250. [PubMed: 23782923]

16. Friberg L, Rosenqvist M, Lip GY. Net clinical benefit of warfarin in patients with atrial fibrillation: a report from the Swedish atrial fibrillation cohort study. Circulation. 2012; 125(19): 2298-2307. [PubMed: 22514252]

17. Avgil Tsadok M, Jackevicius CA, Rahme E, et al. Sex differences in stroke risk among older patients with recently diagnosed atrial fibrillation. JAMA : the journal of the American Medical Association. 2012; 307(18):1952-1958.

18. Pisters R, Lane DA, Nieuwlaat R, et al. A novel user-friendly score (HAS-BLED) to assess 1-year risk of major bleeding in patients with atrial fibrillation: the Euro Heart Survey. Chest. 2010; 138(5):1093-1100. [PubMed: 20299623]

19. Fang MC, Go AS, Chang Y, et al. Death and disability from warfarin-associated intracranial and extracranial hemorrhages. The American journal of medicine. 2007; 120(8):700-705. [PubMed: 17679129]

20. Fang MC, Go AS, Chang Y, et al. Thirty-day mortality after ischemic stroke and intracranial hemorrhage in patients with atrial fibrillation on and off anticoagulants. Stroke; a journal of cerebral circulation. 2012; 43(7):1795-1799.

21. Hart RG, Pearce LA, Aguilar MI. Meta-analysis: antithrombotic therapy to prevent stroke in patients who have nonvalvular atrial fibrillation. Annals of internal medicine. 2007; 146(12):857867. [PubMed: 17577005]

22. Ogilvie IM, Newton N, Welner SA, et al. Underuse of oral anticoagulants in atrial fibrillation: a systematic review. The American journal of medicine. 2010; 123(7):638-645. e634. [PubMed: 20609686]

23. Waldo AL, Becker RC, Tapson VF, et al. Hospitalized patients with atrial fibrillation and a high risk of stroke are not being provided with adequate anticoagulation. Journal of the American College of Cardiology. 2005; 46(9):1729-1736. [PubMed: 16256877]

24. Pugh D, Pugh J, Mead GE. Attitudes of physicians regarding anticoagulation for atrial fibrillation: a systematic review. Age and ageing. 2011; 40(6):675-683. [PubMed: 21821732]

25. Investigators A, Connolly SJ, Pogue J, et al. Effect of clopidogrel added to aspirin in patients with atrial fibrillation. The New England journal of medicine. 2009; 360(20):2066-2078. [PubMed: 19336502]

26. Connolly SJ, Eikelboom J, Joyner C, et al. Apixaban in patients with atrial fibrillation. The New England journal of medicine. 2011; 364(9):806-817. [PubMed: 21309657]

27. Donze J, Clair C, Hug B, et al. Risk of falls and major bleeds in patients on oral anticoagulation therapy. The American journal of medicine. 2012; 125(8):773-778. [PubMed: 22840664]

28. Man-Son-Hing M, Nichol G, Lau A, et al. Choosing antithrombotic therapy for elderly patients with atrial fibrillation who are at risk for falls. Archives of internal medicine. 1999; 159(7):677685. [PubMed: 10218746]

29. Tinetti ME, Speechley M, Ginter SF. Risk factors for falls among elderly persons living in the community. The New England journal of medicine. 1988; 319(26):1701-1707. [PubMed: 3205267]

30. Albrecht JS, Liu X, Baumgarten M, et al. Benefits and Risks of Anticoagulation Resumption Following Traumatic Brain Injury. JAMA internal medicine. 2014

31. Singer DE, Chang Y, Fang MC, et al. The net clinical benefit of warfarin anticoagulation in atrial fibrillation. Annals of internal medicine. 2009; 151(5):297-305. [PubMed: 19721017]

32. Olesen JB, Lip GY, Lindhardsen J, et al. Risks of thromboembolism and bleeding with thromboprophylaxis in patients with atrial fibrillation: A net clinical benefit analysis using a 'real world' nationwide cohort study. Thrombosis and haemostasis. 2011; 106(4):739-749. [PubMed: 21789337]

33. Singer DE, Albers GW, Dalen JE, et al. Antithrombotic therapy in atrial fibrillation: American College of Chest Physicians Evidence-Based Clinical Practice Guidelines (8th Edition). Chest. 2008; 133(6 Suppl):546S-592S. [PubMed: 18574273] 
34. You JJ, Singer DE, Howard PA, et al. Antithrombotic therapy for atrial fibrillation: Antithrombotic Therapy and Prevention of Thrombosis, 9th ed: American College of Chest Physicians EvidenceBased Clinical Practice Guidelines. Chest. 2012; 141(2 Suppl):e531S-575S. [PubMed: 22315271]

35. Mant J, Hobbs FD, Fletcher K, et al. Warfarin versus aspirin for stroke prevention in an elderly community population with atrial fibrillation (the Birmingham Atrial Fibrillation Treatment of the Aged Study, BAFTA): a randomised controlled trial. Lancet. 2007; 370(9586):493-503. [PubMed: 17693178]

36. Rash A, Downes T, Portner R, et al. A randomised controlled trial of warfarin versus aspirin for stroke prevention in octogenarians with atrial fibrillation (WASPO). Age and ageing. 2007; 36(2): 151-156. [PubMed: 17175564]

37. Connolly S, Pogue J, et al. Investigators AWGotA. Clopidogrel plus aspirin versus oral anticoagulation for atrial fibrillation in the Atrial fibrillation Clopidogrel Trial with Irbesartan for prevention of Vascular Events (ACTIVE W): a randomised controlled trial. Lancet. 2006; 367(9526):1903-1912. [PubMed: 16765759]

38. Connolly SJ, Ezekowitz MD, Yusuf S, et al. Dabigatran versus warfarin in patients with atrial fibrillation. The New England journal of medicine. 2009; 361(12):1139-1151. [PubMed: 19717844]

39. Patel MR, Mahaffey KW, Garg J, et al. Rivaroxaban versus warfarin in nonvalvular atrial fibrillation. The New England journal of medicine. 2011; 365(10):883-891. [PubMed: 21830957]

40. Granger CB, Alexander JH, McMurray JJ, et al. Apixaban versus warfarin in patients with atrial fibrillation. The New England journal of medicine. 2011; 365(11):981-992. [PubMed: 21870978]

41. Giugliano RP, Ruff CT, Braunwald E, et al. Edoxaban versus warfarin in patients with atrial fibrillation. The New England journal of medicine. 2013; 369(22):2093-2104. [PubMed: 24251359]

42. Dentali F, Riva N, Crowther M, et al. Efficacy and safety of the novel oral anticoagulants in atrial fibrillation: a systematic review and meta-analysis of the literature. Circulation. 2012; 126(20): 2381-2391. [PubMed: 23071159]

43. Miller CS, Grandi SM, Shimony A, et al. Meta-analysis of efficacy and safety of new oral anticoagulants (dabigatran, rivaroxaban, apixaban) versus warfarin in patients with atrial fibrillation. The American journal of cardiology. 2012; 110(3):453-460. [PubMed: 22537354]

44. Banerjee A, Lane DA, Torp-Pedersen C, et al. Net clinical benefit of new oral anticoagulants (dabigatran, rivaroxaban, apixaban) versus no treatment in a 'real world' atrial fibrillation population: a modelling analysis based on a nationwide cohort study. Thrombosis and haemostasis. 2012; 107(3):584-589. [PubMed: 22186961]

45. Deedwania PC. New oral anticoagulants in elderly patients with atrial fibrillation. The American journal of medicine. 2013; 126(4):289-296. [PubMed: 23369212]

46. Sardar P, Chatterjee S, Chaudhari S, et al. New oral anticoagulants in elderly adults: evidence from a meta-analysis of randomized trials. Journal of the American Geriatrics Society. 2014; 62(5):857864. [PubMed: 24786913]

47. Goodman SG, Wojdyla DM, Piccini JP, et al. Factors associated with major bleeding events: insights from the ROCKET AF trial (rivaroxaban once-daily oral direct factor Xa inhibition compared with vitamin $\mathrm{K}$ antagonism for prevention of stroke and embolism trial in atrial fibrillation). Journal of the American College of Cardiology. 2014; 63(9):891-900. [PubMed: 24315894]

48. Halvorsen S, Atar D, Yang H, et al. Efficacy and safety of apixaban compared with warfarin according to age for stroke prevention in atrial fibrillation: observations from the ARISTOTLE trial. European heart journal. 2014

49. Eikelboom JW, Wallentin L, Connolly SJ, et al. Risk of bleeding with 2 doses of dabigatran compared with warfarin in older and younger patients with atrial fibrillation: an analysis of the randomized evaluation of long-term anticoagulant therapy (RE-LY) trial. Circulation. 2011; 123(21):2363-2372. [PubMed: 21576658]

50. Hohnloser SH, Hijazi Z, Thomas L, et al. Efficacy of apixaban when compared with warfarin in relation to renal function in patients with atrial fibrillation: insights from the ARISTOTLE trial. European heart journal. 2012; 33(22):2821-2830. [PubMed: 22933567] 
51. Fox KA, Piccini JP, Wojdyla D, et al. Prevention of stroke and systemic embolism with rivaroxaban compared with warfarin in patients with non-valvular atrial fibrillation and moderate renal impairment. European heart journal. 2011; 32(19):2387-2394. [PubMed: 21873708] 


\section{KEY POINTS}

- Older age remains one of the strongest risk factors for stroke in patients with atrial fibrillation $(\mathrm{AF})$

- Validated stroke risk stratification schemes, such as the $\mathrm{CHADS}_{2}$ and $\mathrm{CHA}_{2} \mathrm{DS}_{2}$-VASc, should be used to estimate stroke risk and guide anticoagulation decisions in older adults with $\mathrm{AF}$

- Bleeding risk scores, such as HAS-BLED, should not be used to exclude patients from oral anticoagulation (OAC), but rather to identify modifiable bleeding risk factors that can be managed to reduce a patient's risk of bleeding from anticoagulation

- The significant decrease in intracranial bleeding risk with non-vitamin K OACs (NOACs), combined with their fixed dosing schedules and fewer drug-drug interactions, provide potential advantages over VKAs in older patients with AF

- Antiplatelet agents should be reserved primarily for patients who are deemed unsuitable for, or refuse, OAC 


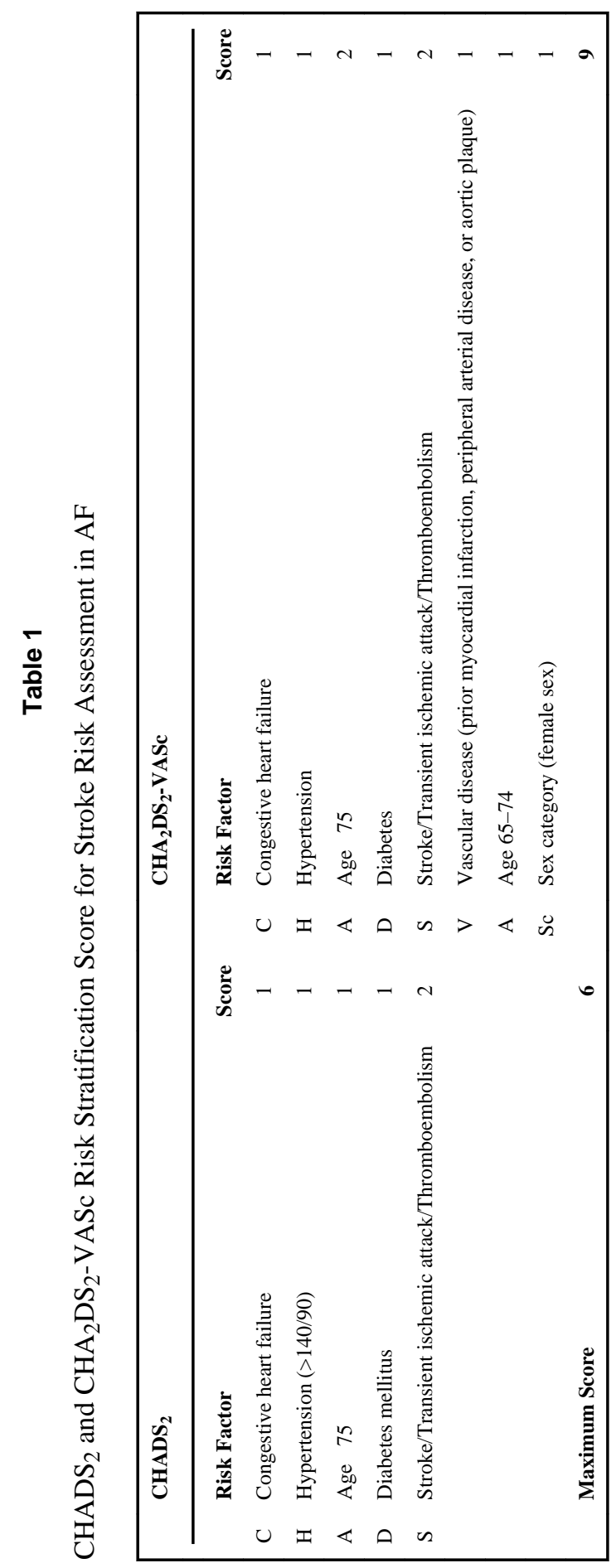

Med Clin North Am. Author manuscript; available in PMC 2016 March 01. 
Table 2

Comparison of Thromboembolic Event Rate by $\mathrm{CHA}_{2} \mathrm{DS}_{2}$-VASc Score per 100 Person Years in Three Prospective Real World Population Cohorts

\begin{tabular}{cccc}
\hline CHA $_{2}$ DS $_{2}$-VASc Score & Friberg $^{\mathbf{1 4}}$ & Singer $^{\mathbf{1 5}}$ & $\begin{array}{c}\text { Olesen }^{\mathbf{1 1}} \\
\text { 1 yr follow-up }\end{array}$ \\
\hline 0 & 0.3 & 0.04 & 0.78 \\
\hline 1 & 0.9 & 0.55 & 2.01 \\
\hline 2 & 2.9 & 0.83 & 3.71 \\
\hline 3 & 4.6 & 1.66 & 5.92 \\
\hline 4 & 6.7 & 2.80 & 9.27 \\
\hline 5 & 10.0 & 4.31 & 15.26 \\
\hline 6 & 13.6 & 4.77 & 19.74 \\
\hline 7 & 15.7 & 4.82 & 21.50 \\
\hline 8 & 15.2 & 7.82 & 22.38 \\
\hline 9 & 17.4 & 16.62 & 23.64 \\
\hline
\end{tabular}

Data from Refs $11,14,15$ 
Table 3

Antithrombotic Therapy Recommendations For Non-Valvular Atrial Fibrillation.

\begin{tabular}{|c|c|c|c|c|}
\hline $\mathrm{CHA}_{2} \mathrm{DS}_{2}$-VASc Score & AHA/ACC/HRS 2014 ${ }^{1}$ & NICE $2014^{8}$ & $\operatorname{CCS} 2012^{8}$ & $\operatorname{ESC~} 2012^{7}$ \\
\hline 0 & No Rx & No Rx & No Rx & No Rx \\
\hline 1 & $\mathrm{OAC}$ or ASA or No Rx & $\begin{array}{c}\text { Female sex: No Rx } \\
\text { Male sex: Consider } \\
\text { OAC }\end{array}$ & $\begin{array}{l}\text { Age } 265 \mathrm{y} \text { : NOAC } \\
\text { preferred over VKA } \\
\text { Vascular disease or } \\
\text { female sex: ASA is a } \\
\text { reasonable alternative }\end{array}$ & $\begin{array}{c}\text { Female sex: No Rx } \\
\text { Age } \searrow 65 \text { or vascular disease: } \\
\text { NOAC } \\
\text { VKA with TTR }>70 \% \text { as an } \\
\text { alternative to NOAC } \\
\text { ASA only for patients who } \\
\text { refuse or cannot tolerate OAC }\end{array}$ \\
\hline$\geq 2$ & $\begin{array}{c}\text { OAC with Warfarin, } \\
\text { Dabigatran, Rivaroxaban, or } \\
\text { Apixaban }\end{array}$ & $\begin{array}{c}\text { OAC with NOAC } \\
\text { or VKA }\end{array}$ & $\begin{array}{l}\text { OAC with NOAC } \\
\text { preferred to VKA }\end{array}$ & $\begin{array}{l}\text { OAC with NOAC } \\
\text { VKA with TTR }>70 \% \text { as an } \\
\text { alternative to NOAC }\end{array}$ \\
\hline
\end{tabular}

Data from Refs 1,7,8 


\section{Table 4}

The HAS-BLED Bleeding Risk Score.

\begin{tabular}{|c|c|c|}
\hline & Risk Factors & Score \\
\hline $\mathbf{H}$ & Hypertension ${ }^{a}$ & 1 \\
\hline $\mathbf{A}$ & Abnormal liver ${ }^{b}$ or kidney function $c$ & 1 or 2 \\
\hline $\mathbf{S}$ & Stroke & 1 \\
\hline B & Bleeding $d$ & 1 \\
\hline $\mathbf{L}$ & Labile $\mathrm{INR}^{e}$ & 1 \\
\hline $\mathbf{E}$ & Elderly $f$ & 1 \\
\hline D & $\operatorname{Drugs}^{g}$ or alcohol ${ }^{h}$ & 1 or 2 \\
\hline
\end{tabular}

$a_{>160 \mathrm{mmHg} \text { systolic }}$

$b_{\text {cirrhosis, bilirubin }>2 \mathrm{xULN}}$ (upper limit of normal), Aspartate aminotransferase/Alanine aminotransferase/Alkaline phosphatase $>3 \mathrm{xULN}$

${ }^{c}$ renal dialysis, history of renal transplant or serum creatinine $22.26 \mathrm{mg} / \mathrm{dL}$

$d_{\text {requir }}$

requiring hospitalization, decrease in Hemoglobin $>2 \mathrm{~g} / \mathrm{L}$ or requiring blood transfusion

$e_{\text {Time in Therapeutic Range }<60 \%}$

$f_{\text {age }}>65$ years

${ }^{g}$ Use of antiplatelet agents or non-steroidal anti-inflammatory drugs

$h_{>8 \text { drinks per week }}$ 
Table 5

Major Bleeding Rates Based on the HAS-BLED Risk Category.

\begin{tabular}{ccc}
\hline Score & Risk Category & Bleeds $/ \mathbf{1 0 0}$ patient years \\
\hline $0-1$ & Low & $1.2-2.8$ \\
2 & Moderate & $3.6-5.4$ \\
$\geq 3$ & High & $6.0-9.5$ \\
\hline
\end{tabular}




\section{Table 6}

Comparison of NOACs for the Prevention of Stroke and Systemic Embolism in AF.

\begin{tabular}{|c|c|c|c|c|}
\hline & Rivaroxaban & Dabigatran & Edoxaban & Apixaban \\
\hline Pro-Drug or Drug & Drug & Pro-Drug & Drug & Drug \\
\hline Target & Factor $\mathrm{Xa}$ & Thrombin & Factor Xa & Factor Xa \\
\hline Mean half-life $\left(t \frac{1}{2}\right)$ & $7-11$ hours & $12-17$ hours & 9-11 hours & $8-15$ hours \\
\hline Tmax & $2-4$ hours & $0.5-2$ hours & 1-2 hours & $3-4$ hours \\
\hline Protein binding & $93 \%$ & $35 \%$ & $55 \%$ & $87 \%$ \\
\hline Dosing Regimen ${ }^{*}$ & 20 mg Daily & $150 \mathrm{mg}$ BID & Daily & $5 \mathrm{mg}$ BID \\
\hline Dose adjustments & $15 \mathrm{mg}$ Daily if $\mathrm{CrCl} 15-50$ & $75 \mathrm{mg} \mathrm{BID}$ if $\mathrm{CrCl} 15$ to 30 & N/A & $\begin{array}{l}2.5 \mathrm{mg} \text { BID if } \geq 2 \text { of the following: } \\
\text { Age } \geq 80 \text { years, weight } \$ 60 \mathrm{~kg} \text {, or } \\
\text { serum creatinine } \geq 1.5 \mathrm{mg} / \mathrm{dL}\end{array}$ \\
\hline Major interactions & P-gp, CYP3A4 & P-gp & P-gp & P-gp, CYP3A4 \\
\hline Estimated renal excretion & $66 \%$ & $80 \%$ & $35 \%$ & $25 \%$ \\
\hline Food Effect & Delayed absorption & Delayed absorption & None & None \\
\hline
\end{tabular}

* FDA-approved dosing, BID, twice daily 


\section{Table 7}

Summary of Key, Randomized Clinical Trials Comparing NOACs to a VKA for the Prevention of Stroke and Systemic Embolism in AF.

\begin{tabular}{|c|c|c|c|c|}
\hline & Rivaroxaban & Dabigatran & Edoxaban & Apixaban \\
\hline Phase III RCT & ROCKET AF & RE-LY & TIMI 48-ENGAGE & ARISTOTLE \\
\hline Population & NVAF and $2 \mathrm{RF}^{*}$ & NVAF and $\geq 1 \mathrm{RF}^{*}$ & NVAF and CHADS2 2 & NVAF and $\geq 1$ RF \\
\hline Patients, $\mathbf{n}$ & 14,264 & 18,113 & 21,105 & 18,201 \\
\hline Study Design & double-blind, double-dummy & PROBE & double-blind, double-dummy & double-blind, double-dummy \\
\hline Primary Objective & Non-Inferior Efficacy & Non-Inferior Efficacy & Non-Inferior Efficacy & Non-Inferior Efficacy \\
\hline Study drug dose(s) & $20 \mathrm{mg}$ daily & $110 \mathrm{mg}$ or $150 \mathrm{mg}$ & $60 \mathrm{mg}$ daily & $5 \mathrm{mg}$ BID \\
\hline Renal dose & $15 \mathrm{mg}$ daily & None & $30 \mathrm{mg}$ daily & $2.5 \mathrm{mg}$ BID \\
\hline Age, $\mathbf{y}$ & 73.0 & 71.5 & 72.0 & 70.0 \\
\hline Male Gender, $\%$ & 60.3 & 63.6 & 61.9 & 64.7 \\
\hline CHADS $\mathbf{2}$ Score & 3.5 & 2.1 & 2.8 & 2.1 \\
\hline TTR, $\%$ & 55 & 64 & 65 & 62 \\
\hline Aspirin Use, $\%$ & 36.5 & 39.8 & 29.3 & 30.9 \\
\hline
\end{tabular}

risk factors (RF): age $\geq 75 \mathrm{y}$; history of stroke, transient ischemic attack, or systemic embolism; symptomatic heart failure and/or left-ventricular ejection fraction $<40 \%$; diabetes mellitus; and/or need for antihypertensive treatment.

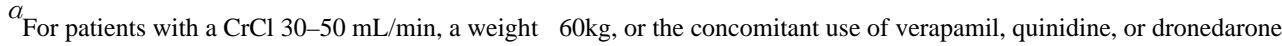

PROBE: prospective open-label blinded endpoint evaluation 
Table 8

Considerations when Choosing Between a VKA or a NOAC for Older Patients with AF.

\begin{tabular}{|c|c|c|}
\hline Consideration or Factor & Potentially Preferred OAC & Comment \\
\hline $\begin{array}{l}\text { Severe Renal Impairment (e.g. CrCl 15-30 } \\
\mathrm{mL} / \mathrm{min})\end{array}$ & $\begin{array}{c}\text { VKA, Reduced Dose Dabigatran } 75 \mathrm{mg} \\
\text { BID, or Reduced Dose Rivaroxaban } \\
\text { 15mg Daily }\end{array}$ & $\begin{array}{l}\text { VKA elimination is independent of any renal } \\
\text { impairment }\end{array}$ \\
\hline End-Stage Kidney Disease & VKA & $\begin{array}{l}\text { VKA elimination is independent of any renal } \\
\text { impairment }\end{array}$ \\
\hline History of ICH & $\begin{array}{c}\text { Dabigatran, Rivaroxaban, Apixaban, } \\
\text { Edoxaban }\end{array}$ & $\begin{array}{l}\text { All NOACs reduced the risk of ICH compared to } \\
\text { VKA }\end{array}$ \\
\hline Mechanical Heart Valves & VKA & NOACs only approved in NVAF \\
\hline $\begin{array}{l}\text { Unstable INR or Inability to Comply with } \\
\text { Regular INR Monitoring }\end{array}$ & $\begin{array}{c}\text { Dabigatran, Rivaroxaban, Apixaban, } \\
\text { Edoxaban }\end{array}$ & $\begin{array}{c}\text { Predictable Pharmacokinetics without Need for } \\
\text { Routine Monitoring }\end{array}$ \\
\hline Poor Adherence to Taking Medication & VKA & $\begin{array}{l}\text { Longer Half-Life, Ability to Monitor Compliance } \\
\text { with INR }\end{array}$ \\
\hline $\begin{array}{c}\text { Concomitant Use of Azole Antimycotics or } \\
\text { Ritonavir }\end{array}$ & Dabigatran, VKA & $\begin{array}{l}\text { Azole Antimycotics or Ritonavir Increase Blood } \\
\text { Concentration of FXa Inhibitors }\end{array}$ \\
\hline Dyspepsia & $\begin{array}{l}\text { VKA, Rivaroxaban, Apixaban, } \\
\text { Edoxaban }\end{array}$ & High Incidence of Dyspepsia with Dabigatran \\
\hline $\begin{array}{l}\text { Poor Compliance with Twice Daily } \\
\text { Medication }\end{array}$ & VKA, Rivaroxaban & Once Daily Dosing Regimen \\
\hline History of GI Bleeding & VKA, Apixaban & $\begin{array}{l}\text { Higher Rates of GI Bleeding with Dabigatran, } \\
\text { Rivaroxaban, and Edoxaban }\end{array}$ \\
\hline Cost Concerns & VKA & NOACs may be Cost Prohibitive to Some Patients \\
\hline
\end{tabular}

